\title{
香鱼补体成分 $\boldsymbol{C} 9$ 基因的克隆、序列分析及表达
}

\author{
孔铖将, 黄左安, 陈 炿", 史雨红, 陆新江 \\ (宁波大学 应用海洋生物技术教育部重点实验室，浙江 宁波 315211）
}

\begin{abstract}
摘要: 补体成分 $\mathrm{C} 9$ 是构成膜攻击复合体引起靶细胞溶解破坏的重要组成成分。该文测定了香鱼 $C 9(a C 9)$ 基 因的 cDNA 全序列, 序列全长 2125 个核苷酸, 编码一个由 592 个氨基酸组成、相对分子质量为 $6.56 \times 10^{4}$ 的前体 蛋白, $\mathrm{N}$ 端 22 个氨基酸为信号肽序列。序列分析表明, $\mathrm{aC} 9$ 与虹鳟 $\mathrm{C} 9$ 的氨基酸同源性最高，达 $56.8 \%$ ，与其它鱼类 C9 的同源性介于 $40.9 \%$ 53.8\%之间。 aC9 在健康香鱼肝、脾、肠、鳃和肌肉有表达，其中在肝内的表达量最高。 实时荧光定量 PCR 的结果显示, 鳗利斯顿氏菌侵染 $4 \mathrm{~h}$ 后, 肝中 $a C 9 \mathrm{mRNA}$ 表达量显著上调, 并随着时间的推移 在 $16 \mathrm{~h}$ 时达到峰值。Western blotting 分析的结果显示, 鳗利斯顿氏菌侵染后香鱼血清中的 aC9 蛋白随着时间的推 移呈显著上调。以上结果表明, 香鱼肝组织 $C 9$ 基因表达变化与鳗利斯顿氏菌的侵染密切相关，揭示了 C9 在鱼类 抗细菌免疫反应中具有重要的作用。
\end{abstract}

关键词：补体成分 C9; 香鱼; 鳗利斯顿氏菌; 实时苂光定量 PCR; Western blotting 中图分类号: Q785; Q959.499; Q516＼cjkstart文献标志码：A＼cjkstart文章编号：0254-5853-(2012)02-0151-07

\section{Molecular cloning, sequence analysis and expression of ayu complement component $C 9$ gene}

\author{
KONG Cheng-Jiang, HUANG Zuo-An, CHEN Jiong ${ }^{*}$, SHI Yu-Hong, LU Xin-Jiang \\ (Key laboratory of Applied marine Biotechnology, Ministry of Education, Ningbo University, Ningbo 315211, China)
}

\begin{abstract}
C9, a component of the membrane attack complex, participates in the final stage of the complement cascade which lyses foreign organisms by disrupting the integrity of their cell membranes. In the present study, a full-length ayu C9 (aC9) cDNA was cloned which contains 2,125 nucleotides and encodes a protein of 592 amino acids. A signal peptide was deposited in the N-terminal 22 residues. The deduced amino acid sequence of aC9 showed $56.8 \%$ identity to the C9 of rainbow trout, and $40.9 \%$ to $53.8 \%$ identity to the C9 of other teleosts. RT-PCR analysis demonstrated that the mRNA of $a C 9$ was expressed in the liver, spleen, intestine, gill and muscle of healthy ayu fish with the highest level in the liver. Quantitative RT-PCR analysis showed that $a C 9$ transcripts were significantly up-regulated in the liver at $4 \mathrm{~h}$ post Listonella anguillarum infection, peaked at $16 \mathrm{~h}$ post injection. Western blotting analysis revealed that serum aC9 significantly increased in Listonella anguillarum infected ayu fish. Our results suggested that aC9 may play an important role in fish immune response of anti-bacteria.
\end{abstract}

Key words: Complement component C9; Ayu; Listonella anguillarum; RT-qPCR; Western blotting

补体系统参与机体防御与炎症反应, 通过溶解 病原体或募集吞噬细胞的方式，清除大部分病原 体。补体系统通过多种途径调控免疫功能, 如炎症 细胞的趋化作用、增强巨噬细胞和嗜中性粒细胞的 吞噬作用、肥大细胞脱粒、调节 $\mathrm{B} 、 \mathrm{~T}$ 细胞的免疫 应答和增强抗原免疫原性等(Dunkelberger \& Song,
2010; Toapanta \& Ross, 2006)。补体系统除了作为先 天免疫与获得性免疫的补充之外, 还调节组织再生 (Rutkowski et al, 2010)、肿瘤生长(Qu et al, 2009)以 及某些病理状况, 如非典型性溶血尿毒症和老年性 黄斑退化症等(Wagner \& Frank, 2010)。与哺乳动物 类似, 鱼类的补体激活主要包括三条途径: 经典途

收稿日期: 2011-11-21; 接受日期: 2011-12-26

基金项目：教育部新世纪优秀人才支持计划项目(NCET-08-0928); 宁波市自然科学基金项目(2010A610001)

*通信作者(Corresponding author), Tel: 0574-87609571, E-mail: jchen1975@163.com

第一作者简介：孔铖将(1986一), 男, 浙江绍兴人, 硕士研究生, 研究方向: 分子生物学; Tel: 13586883124; E-mail: kongchengjiang@163.com 
径(Classical pathway)、旁路途径(Alternative pathway) 和凝集素途径(Lectin pathway)(Endo et al，2011; Sarmar \& Ward，2011)。补体激活的后期成分 C5b C9 形成膜攻击复合物 (Membrane attack complex, MAC), 可通过破坏病原体细胞膜的完整 性致使细胞溶解(Muller-Eberhard, 1986; Fosbrink et al, 2005)。哺乳动物的补体成分 C9 是一类单链糖蛋 白, 糖链含量占总相对分子质量的 $7.8 \%$ (Biesecker et al, 1982), 参与靶细胞表面 MAC 的形成, 是补体 系统激活并攻击破坏靶细胞的重要补体固有成分。 近年来, 多种鱼的 C9 研究已被报道, 如河豚 (Fugu rubripes)(Yeo et al, 1997)、牙 鲜 (Paralichthys olivaceus)(Katagiri et al, 1999)、虹鳟(Oncorhynchus mykiss)(Stanley \& Herz, 1987; Tomlinson et al, 1993; Chondrou et al, 2006)、草鱼(Ctenopharyngodon idella)(Li et al, 2007)和斑马鱼(Danio rerio)(Encinas et al, 2010)等。

香鱼(Plecoglossus altivelis)属胡瓜鱼目香鱼科, 是东亚地区一种小型经济名贵鱼类, 在中国沿海各 地均有分布。由于高密度养殖, 种质退化等原因导 致病害发生频繁, 其中以鳗利斯顿氏菌(Listonella anguillarum)最为严重( Li et al, 2009)。由于香鱼对养 殖环境要求较高, 且绿色养殖已经成为一种趋势, 传统的抗生素等药物防治已经越来越不适应最新 的养殖要求, 因此, 迫切需要深入研究香鱼免疫相 关基因, 来指导香鱼病害防治(Uenobe et al, 2007; Chen et al, 2008)。本研究通过文库测序结合 RACE 的方法成功获得了香鱼 $C 9(a C 9)$ 基因的 cDNA 全序 列, 并分析了其序列特征及 mRNA 的组织表达特征, 同时通过原核表达制备了小鼠抗 $\mathrm{aC} 9$ 血清, 并以此 研究了鳗利斯顿氏菌侵染后香鱼血清中 $\mathrm{aC} 9$ 的表达 变化, 为进一步深入研究 $\mathrm{C} 9$ 在鱼类抗细菌免疫中 的作用奠定了基础。

\section{1 材料与方法}

\section{1 实验材料与试剂}

实验材料: 健康香鱼 50 尾, 个体重 $20 \sim 25 \mathrm{~g}$, 购 自宁波水产大世界; ICR 小鼠购自宁波大学医学院 实验动物中心; 鳗利斯顿氏菌香鱼分离株 ayu-H080701、大肠杆菌 TG1、BL21 pLys E 和原核 表达载体 pET-28a 由本实验室保存。

试剂: Gel Extraction Kit 购自 Omega 公司; 辣 根酶标记山羊抗小鼠 $\operatorname{IgG}$ 购自北京中山金桥生物技
术有限公司; 肽 N-糖苷酶 F (PNGase F) 购自 New England Biolabs 公司; RNAiso、Oligotex-dT30<super> mRNA Purification Kit、AMV 逆转录酶、MMuLV 逆转录酶、Ex Taq DNA 聚合酶、100 bp DNA Ladder Marker、DNA Ligation Kit Ver.2.0、cDNA Library Construction Kit 和 SYBR Premix Ex Taq 等试剂盒购 自 Takara 公司; ECL 化学发光试剂盒、显影定影试 剂盒、柯达 X-OMAT BT 胶片和压片暗盒购自碧云 天生物技术研究所; 引物合成及序列测定由上海英 骏生物工程公司完成; 其他常规化学药剂均为国产 分析纯。

\section{2 样品制备}

选取 4 尾健康香鱼, 采集肝、脾、肾、脑、心、 鳃、肌肉、肠等组织, 液氮保存, 用于 $a C 9$ 基因 mRNA 的组织表达特征分析。剩余的香鱼分为实验 组和对照组, 各 23 尾, 实验组每尾香鱼腹腔注射 $100 \mu \mathrm{L}$ 鳗利斯顿氏菌悬液 $\left(1.0 \times 10^{5} \mathrm{CFU} / \mathrm{mL} \mathrm{PBS}\right)$, 对照组每尾香鱼注射 $100 \mu \mathrm{L}$ 无菌 PBS。注射后 $24 \mathrm{~h}$, 随机挑选实验组香鱼 3 尾进行病原菌分离, 确认接 种效果( Li et al, 2009)。实验组和对照组香鱼分别于 腹腔注射后 4、8、16、24 和 $36 \mathrm{~h}$ 取样, 每次 3 尾/ 组, 其中尾静脉抽取的血液于 $4{ }^{\circ} \mathrm{C}$ 静置 $4 \mathrm{~h}$, 析出 血清离心后 $-70{ }^{\circ} \mathrm{C}$ 保存, 其余样品, 如肝组织等于 液氮保存。

\section{3 香鱼 $a C 9$ 基因 $\mathrm{cDNA}$ 全序列获得及序列分析}

采用文库测序的方法获得 $a C 9$ 基因 $\mathrm{cDNA}$ 的部 分序列(Huang et al, 2011), 结合 RACE 方法扩增获 得 $a C 9$ 基因 cDNA $5^{\prime}$-和 $3^{\prime}$-末端序列, 序列拼接后得 到 $a C 9$ 基因 cDNA 全序列。信号肽序列预测采用 SignalP 3.0 在线软件(http://www.cbs.dtu.dk/services/ SignalP/), 结构特征分析采用 Scanprosite (http:// www.expasy.org/tools/scanprosite/)和 Motifscan 在线 程序 (http://myhits.isb-sib.ch/cgi-bin/motif_scan), 多重序列比对、进化分析和系统进化树构建采用 MEGA 4.0 (Tamura et al, 2007)。

\section{4 香鱼 $a C 9$ 基因 mRNA 的组织表达特征分析}

组织表达特征分析相关的 RNA 提取、DNase I 处理和第一链 cDNA 合成等方法详见文献(Huang et $\mathrm{al}, 2011$ )。根据 $a C 9$ 基因 $\mathrm{cDNA}$ 序列跨内含子设计 一对扩增引物 C9ex10F (5'-CCTGAATTCGAAGGA $\left.C T G G C-3^{\prime}\right)$ 和 C9ex11R (5'-CAGAGAGTTGGCCTG $\left.T C T T G-3^{\prime}\right)$, 预期扩增片段长 $160 \mathrm{bp}$ 。内标采用看家 基因 $\beta$-actin, 扩增引物为 $\mathrm{pActin} 2(+) / \mathrm{pActin} 2(-)$, 预 
期扩增片段长 234 bp (Huang et al, 2011)。PCR 扩增 以合成的各组织 $\mathrm{cDNA}$ 为模板, $25 \mu \mathrm{L}$ 的反应体系如 下： cDNA 模板 $25 \mathrm{ng}, 10 \times E x$ PCR 缓冲液 $2.5 \mu \mathrm{L}$, $\mathrm{dNTP}$ 混合物(各 $2.5 \mathrm{mmol} / \mathrm{L}$ ) $2 \mu \mathrm{L}$, 正向和反向引 物 $(10 \mu \mathrm{mol} / \mathrm{L})$ 各 $1 \mu \mathrm{L}$, Ex Taq DNA 聚合酶 $1.25 \mathrm{U}$, 双蒸水补足 $25 \mu \mathrm{L} 。 94{ }^{\circ} \mathrm{C}$ 变性 $2 \mathrm{~min}$ 后, 按以下程 序进行 28 个循环: $94{ }^{\circ} \mathrm{C}$ 变性 $30 \mathrm{~s}, 58{ }^{\circ} \mathrm{C}$ 退火 $30 \mathrm{~s}$, $72{ }^{\circ} \mathrm{C}$ 延伸 $30 \mathrm{~s}$, 循环结束后 $72{ }^{\circ} \mathrm{C}$ 继续延伸反应 7 $\min 。 \mathrm{PCR}$ 产物用 $2 \%$ 琼脂糖凝胶电泳分离, 溴化乙 锭染色检测。

\section{5 与鳗利斯顿氏菌侵染相关的香鱼肝组织 $\mathrm{aC} 9$ 基因 mRNA 的表达变化}

取腹腔注射后不同时间的香鱼肝组织，检测 $\mathrm{aC}$ 基因 mRNA 表达量的变化。每一取样时间点的 实验组和对照组鱼各 3 尾, 分别抽提肝组织总 RNA。RNA 抽提、DNase I 处理和第一链 cDNA 合 成等方法同文献(Huang et al, 2011)。实时苂光定量 PCR (RT-qPCR)采用 $25 \mu \mathrm{L}$ 反应体系, 含 SYBR Premix Ex Taq (2×)缓冲液 $12.5 \mu \mathrm{L}$, 正向和反向引 物 $(10 \mu \mathrm{mol} / \mathrm{L})$ 各 $1 \mu \mathrm{L}$, 模板 $0.5 \mu \mathrm{L}$, 灭菌水 $10 \mu \mathrm{L}$ 。 扩增反应在 Stratagene Mx3000P 苂光定量 PCR 仪上 进行, $94{ }^{\circ} \mathrm{C}$ 变性 $180 \mathrm{~s}$ 后, 按以下程序进行 40 个循 环: $94{ }^{\circ} \mathrm{C} 30 \mathrm{~s}, 58{ }^{\circ} \mathrm{C} 30 \mathrm{~s}, 72{ }^{\circ} \mathrm{C} 30 \mathrm{~s}$ 。为确保特异性 扩增, PCR 结束后对扩增产物进行熔解曲线分析, 流程为 $94{ }^{\circ} \mathrm{C} 30 \mathrm{~s}, 72{ }^{\circ} \mathrm{C} 60 \mathrm{~s}, 95{ }^{\circ} \mathrm{C} 30 \mathrm{~s}$ 。每一个样 品技术重复 3 次。荧光定量结果由程序 MxPro 3.2 读取, 采用相对标准曲线法 $2^{-\Delta \Delta \mathrm{Ct}}$ (Livak \& Schmittgen, 2001)分析相对定量结果。

\section{6 香鱼 $\mathrm{aC9}$ 的原核表达和抗血清制备}

设计原核表达引物 $\mathrm{pET}-28 \mathrm{a}-\mathrm{C} 9(+)\left(5^{\prime}-\mathrm{CCATATG}\right.$ AGGACCTTCTCTACTGT-3') 和 pET-28a-C9(-)(5'GGGATCCTTAACAGTAATCGTCGCTGC-3'), 以香 鱼肝组织 $\mathrm{cDNA}$ 为模板, $\mathrm{PCR}$ 扩增 $\mathrm{aC}$ 基因全长开 放阅读框架，预期大小产物(1 $790 \mathrm{bp}$ )经 $1 \%(\mathrm{w} / \mathrm{v})$ 琼脂糖凝胶电泳分离后, 切胶纯化。纯化产物经 $N d e \mathrm{I}$ 和 $B a m \mathrm{H}$ I 双酶切, 插入 pET-28a 载体, 获得 重组质粒 pET-28a-aC9。转化有 pET-28a-aC9 的大 肠杆菌 BL21 pLys E 经 IPTG 诱导后, SDS-PAGE 检测。预期大小的诱导表达蛋白条带切胶纯化后免 疫小鼠，制备抗血清 (Huang et al, 2011)。

\section{7 血清蛋白的去糖基化}

根据糖苷酶试剂盒说明, 取目标蛋白 $9 \mu \mathrm{L}$ (约 $20 \mu \mathrm{g}$ ), 加入 $10 \times$ 糖蛋白变性缓冲液 $1 \mu \mathrm{L}, 100{ }^{\circ} \mathrm{C}$ 变
性 $10 \mathrm{~min}$, 冷却到室温后, 加入 $1 \mu \mathrm{L}$ 的 $10 \times \mathrm{G} 7$ 缓冲 液, $1 \mu \mathrm{L}$ 的 $10 \%$ NP-40, $1 \mu \mathrm{L}$ 的 PNGase F $(500$ $\mathrm{U} / \mu \mathrm{L}), 37{ }^{\circ} \mathrm{C}$ 反应 $1 \mathrm{~h}$ 。加入上样缓冲液处理样品后, Western blotting 鉴定目标蛋白电泳迁移情况。

\section{8 蛋白质印迹}

蛋白样经 SDS-PAGE 电泳分离后, 转 NC 膜后 用 ECL 化学发光法检测(Huang et al, 2011)。一抗为 前所制备的小鼠抗 $\mathrm{aC} 9$ 抗血清, 二抗为辣根过氧化 物酶标记山羊抗小鼠 IgG。

\section{9 数据分析}

实验结果表示为平均值土标准误, 采用 SPSS 软 件(13.0)中的单因素方差分析(One-way ANOVA)进 行统计, $P<0.05$ 为显著差异。

\section{2 结 果}

\section{1 香鱼 $a C 9$ 基因 cDNA 序列分析}

$a C 9$ 基因 cDNA 序列全长 2125 个核苷酸 (GenBank 登录号: FR714486), 编码一个由 592 个 氨基酸组成、相对分子质量为 $6.56 \times 10^{4}$ 的前体蛋白。 前体蛋白 $\mathrm{N}$ 端 22 个氨基酸为信号肽序列, 成熟肽 $\mathrm{aC} 9$ 预测相对分子质量为 $6.34 \times 10^{4}$ 。结构域分析显 示，该蛋白具有已知的 C9 特征性的结构( $\mathrm{Li}$ et al, 2007; Katagiri et al, 1999; Tomlinson et al, 1993; Yeo et al, 1997), 包括 TSP1 (thrombospondin type-1)结构 域(Asp41 Asn94)、LDLa (low-density lipoprotein receptor class A)结构域(Leu100 Asp135)、MACPF (MAC/perforin)结构域(Val138 Lys503) 和 EGF-like (epidermal growth factor like) 结 构 域 (Cys522 Cys533)。多重序列比对发现, 鱼类和哺乳 类 $\mathrm{C} 9$ 在蛋白的 $\mathrm{C}$ 端有较大差异, 鱼类 $\mathrm{C} 9$ 在此区域 还具有另一个 TSP1 结构域(Lys549 Pro586), 但哺 乳动物中没有(图 1)。糖基化位点预测揭示, $\mathrm{aC} 9$ 序 列存在 1 个潜在的 $\mathrm{N}$-糖基化位点(Asn254)。

氨基酸序列比较表明, $\mathrm{aC} 9$ 与虹鳟 $\mathrm{C} 9$ 同一性最 高, 达 $56.8 \%$, 与其它鱼类 C9 的同一性介于 40.9\% 53.8\%之间，与哺乳动物 C9 的同一性低于 $32.8 \%$ 。系统进化树分析揭示，鱼类 C9 和哺乳动物 $\mathrm{C} 9$ 分别成族, 在鱼类 C9 中, 斑马鱼和草鱼 C9 紧密 成簇，区别于其他鱼类 $\mathrm{C} 9, \mathrm{aC} 9$ 与虹鳟 $\mathrm{C} 9$ 的进化关 系最近(图 2)。

\section{2 香鱼 $a C 9$ 基因 $\mathrm{mRNA}$ 组织表达特征}

基因组 DNA 经 DNase I 处理后, PCR 扩增 $\mathrm{aC} 9$ 和 $\beta$-actin，没有发现明显的条带，说明处理后 
TSP1

Plecoglossus altivelis Paralichthys olivaceus Takifugu rubripes

Fundulus heteroclitus Xiphophorus hellerii Oncorhynchus mykiss Ctenopharyngodon idell Damio rerio

Bos tourus

Sus scrofa

Hono sapiens

Equus caballus

Oryctolagus cuniculus

Rattus norvegicus
508 ONGGSWIL ID GSC SCLCTPE FEGL ACQ TL K SDKRRPT----SWTEKGNW ACWS AWSSCSAGRRQRSRLCKTGQL- SGA TCLGNPS SDD YC 592 470 HNGGTLAMD GKC MCLC SFL FEGMOCQNFKGDKAQHA-GTRFTWWEGNWSCWS AWSSCSGGERTRARNCMTDGL-PDANCRGDTN SDEFC 558 498 HNGGTLALLDGKC ICIC SIL FEGLOCQNFKGDKAKNP-AMRPAVTQEGNWSCWS SWSNCQGQKRSRTRYCNTEGT-LGAECRGEIRSEE YC 586

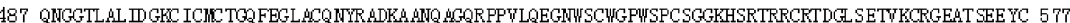
501 HNGGTLALD DGKC ICNCPEL FEGLOCQNFK ADKA SHQ-GKKPTP LQEGNWSCWG SWSACSGGKRSRTRRCNTDGLGP SWTKKGEL T SED YC 590 512 HNGGSLALLDGKCLCLCLFQFEGLACQDAKADNNWNTKTPVESWPQEGNWSCWA AHSGCSGGKRIRTRSCNTQGL - SDA TCRGDIVTED YC 601 566 QNGGTVIQTIGECKCNCLFGSEGWHCQ IW NENWKCK----SFEQLGNWCWTFWSPCSGRRRKTRTCNTRGV-PNG ICKGDTT SED YC 650 589 QNGGTWIQD GQCKCICL LF SEG WHCQ ID MENDKKK----TFEQLGNWCWW AWSHCSGGRRTRSRSCNWRGL - TNG ICKGDKT SED YC 673

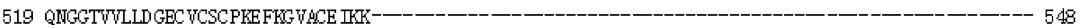



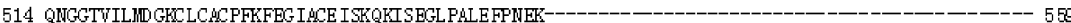

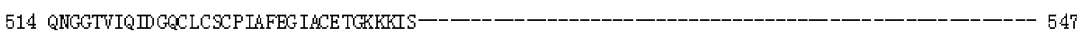

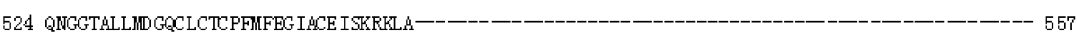

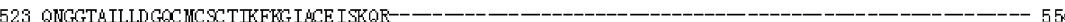

图 1 一些鱼类和哺乳动物 $\mathrm{C} 9$ 的 $\mathrm{C}$ 末端区序列的比对

Fig.1 Multiple alignment of the C-terminal amino acid sequences of fish and mammalian C9

各物种 C9 序列登录号分别为: 香鱼(FR714486)、虹鳟(NM_001124426)、红鳍东方鲀(U87241)、底鲜(AY495671)、牙鲆(AB020963)、草鱼(EF363857)、 斑马鱼(BX510649)、剑尾鱼(HQ714333)、大鼠(U49071)、牛(BC105174)、人(BC020721)、马(U19381)、兔(NM_001082346)和猪(NM_001097448)。 Accession numbers of sequences used are: Plecoglossus altivelis, FR714486; Oncorhynchus mykiss, NM_001124426; Takifugu rubripes, U87241; Fundulus heteroclitus, AY495671; Paralichthys olivaceus, AB020963; Ctenopharyngodon idella, EF363857; Danio rerio, BX510649; Xiphophorus hellerii, HQ714333; Rattus norvegicus, U49071; Bos taurus, BC105174; Homo sapiens, BC020721; Equus caballus, U19381; Oryctolagus cuniculus, NM_001082346; Sus scrofa, NM_001097448.

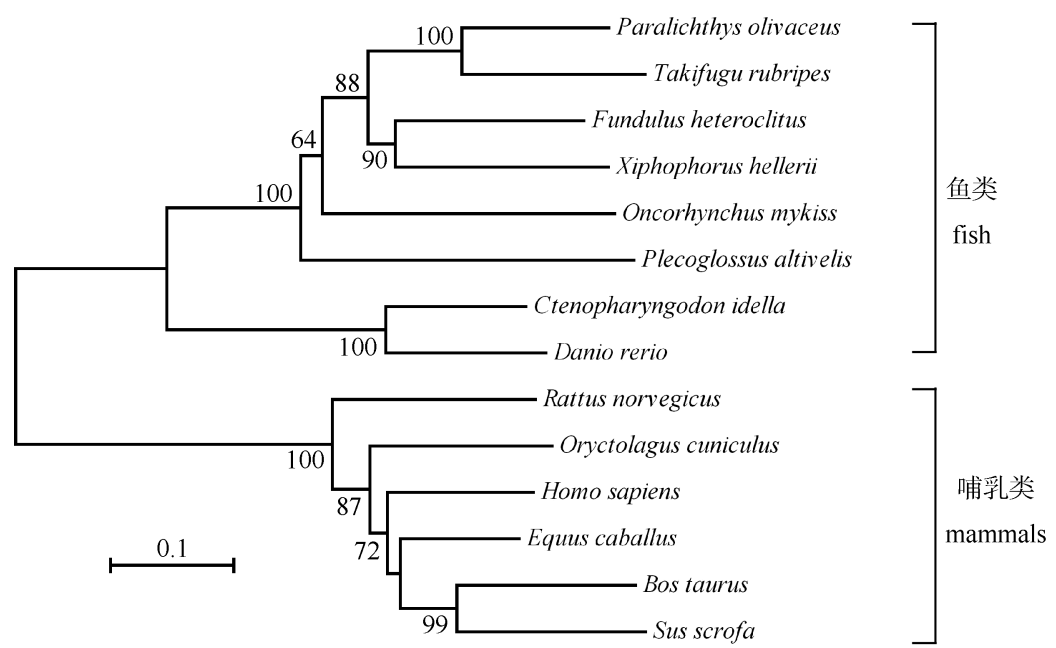

图 2 基于 $\mathrm{NJ}$ 法构建的动物 $\mathrm{C} 9$ 蛋白氨基酸序列系统进化树

Fig.2 Phylogenetic tree of the amino acid sequences of animals C9 using neighbor-joining method 分叉处数值表示 1000 次重复抽样所得到的置信度, 只显示置信度 $60 \%$ 以上的数值; 标尺长度表明每个位点发生 0.1 次置换。各物种 $\mathrm{C} 9$ 序列登录号 详见图 1 。

The values at the forks indicate the percentage of trees in which this grouping occurred after bootstrapping the data ( 1000 replicates; shown only when $>60 \%$ ). The scale bar shows the number of substitutions per site. GenBank Accession numbers of sequences used are listed in Fig.1.

的基因组 DNA 并不对 RT-PCR 结果产生干扰(图 3)。各组织样品 CDNA 的 PCR 扩增结果表明, 健康 香鱼 $a C 9$ 基因 $\mathrm{mRNA}$ 主要在肝组织中表达, 在脾和 肠组织中也有一定量表达，鳃和肌肉中有微量表达， 而其他组织未扩增到可见条带(图 3)。

\section{3 鳗利斯顿氏菌侵染后肝组织 $a C 9$ 基因 mRNA} 的表达变化

在所检测的各组织中, $a C 9$ 基因的 mRNA 主要 在肝中表达, 我们随后用 RT-qPCR 方法进一步研

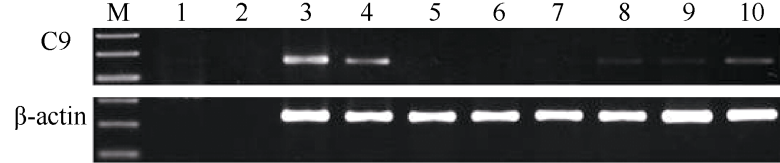

图 3 香鱼 $\mathrm{aC} 9$ 基因 mRNA 的组织表达特征

Fig.3 The mRNA expression pattern of ayu aC9 M: 100 bp DNA Ladder Marker，条带从上到下分别为 $300 、 200$ 和 100 bp; 1：香鱼基因组 DNA (DNase I 处理); 2：无模板阴性对照; 3：肝; 4：脾; 5: 肾; 6: 脑; 7: 心; 8: 鳃; 9: 肌肉; 10: 肠。

M: 100 bp DNA Ladder Marker, the three bands marks 300, 200 and 100 bp respectively; 1: ayu genomic DNA treated with DNase I; 2: without template, negative control; 3: liver; hepatopancreas; 4: spleen; 5: kidney; 6: brain; 7: heart; 8: gill; 9: muscle; 10: intestine. 


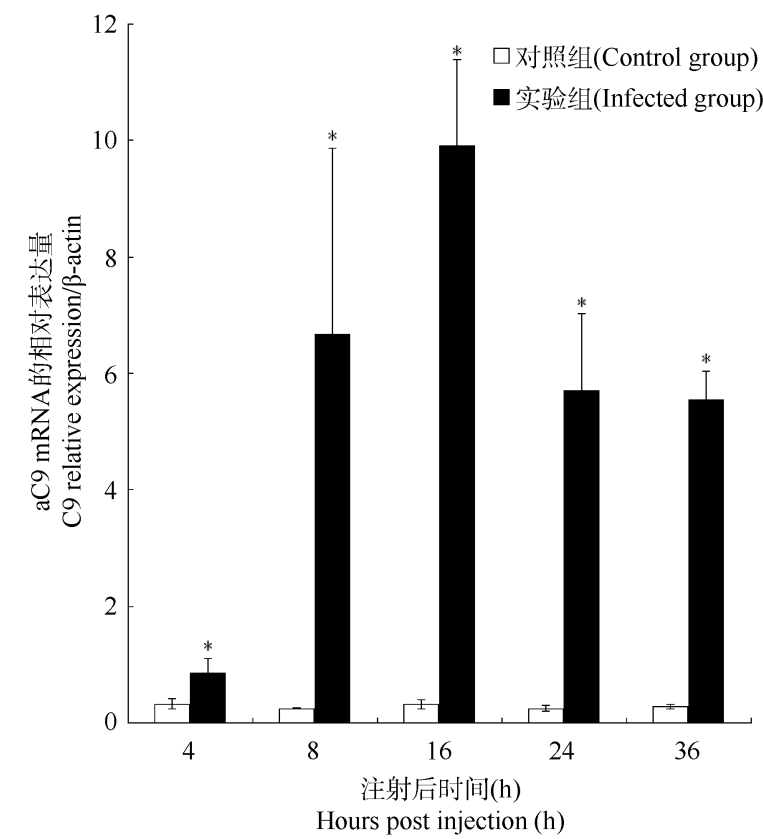

图 4 鳗利斯顿氏菌侵染后香鱼肝组织 $\mathrm{aC}$ 基因 mRNA 的表达变化

Fig.4 Dynamic expression of ayu aC9 mRNA in ayu liver during Listonella anguillarum infection

*: 显著性差异(Significant differences) $(n=3)(P<0.05)$ 。

究与细菌感染相关的肝组织 $a C 9$ 基因 mRNA 表达 量的变化。结果表明, 细菌感染 $4 \mathrm{~h}, a C 9$ 基因 mRNA 表达量显著上调, 达到对照组的 2.65 倍, $16 \mathrm{~h}$ 时表 达量达到峰值, 为对照组的 31.97 倍, 此后表达量下 降, 但直到 $36 \mathrm{~h}$, 仍显著高于对照组(19.79 倍)（图 4)。

\section{4 香鱼 $\mathrm{aC} 9$ 的原核表达及血清中成熟肽的糖基 化验证}

重组菌体经 IPTG 诱导表达、超声波裂解后，在 SDS-PAGE 分离胶中观察到一条相对分子质量约为 $6.8 \times 10^{4}$ 的诱导表达蛋白条带(图 5a), 与计算的 $\mathrm{aC} 9$ 融合蛋白相对分子质量吻合 $\left(6.78 \times 10^{4}\right)$ 。该蛋白条带 切胶纯化后免疫小鼠，制备抗血清。

据软件预测, $\mathrm{aC} 9$ 序列中存在一个潜在的 N-糖 基化位点 Asn254。Western blotting 结果表明，血清 中的 $\mathrm{aC} 9$ 成熟肽相对分子质量约为 $6.76 \times 10^{4}$, 比计 算值大 $4.2 \times 10^{3}$ 左右，而经 PNGase $\mathrm{F}$ 处理后，相对 分子质量转变为 $6.35 \times 10^{4}$, 与计算值基本吻合。揭 示 $\mathrm{aC} 9$ 存在翻译后 $\mathrm{N}$-糖基化修饰(图 5b)。糖链含量, 占总分子量的 $6.07 \%$ 。

\section{5 鳗利斯顿氏菌侵染后香鱼血清 $\mathrm{aC} 9$ 的含量变化} 用前所制备的香鱼 $\mathrm{aC} 9$ 多抗，Western blotting
分析鳗利斯顿氏菌侵染 $0 、 4 、 8 、 16 、 24$ 和 $36 \mathrm{~h}$ 时 的香鱼血清蛋白样品(图 6)。结果表明，细菌侵染后，

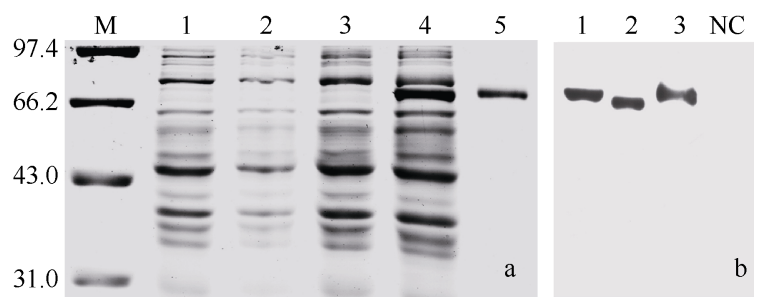

图 5 香鱼 $\mathrm{aC} 9$ 基因的原核表达和血清中成熟肽的 糖基化验证

Fig.5 Prokaryotic expression of ayu aC9 and the confirmation of its posttranslational $\mathrm{N}$-glycosylation

a) SDS-PAGE 检测香鱼 $\mathrm{aC} 9$ 基因的原核表达，考马斯亮蓝 G-250 染色。 $\mathrm{M}$ : 低相对分子质量标准蛋白质 $\left(\times 10^{3}\right)$; 1: BL21 plysE, IPTG 诱导; 2: 转化有 pET-28a 质粒的 BL21 plys E, IPTG 诱导; 3 : 转化有 pET-28a-aC9 重组质粒的 BL21 plys E, IPTG 未诱导; 4: 转化有 pET-28a-aC9 重组质粒 的 BL21 plys E, IPTG 诱导; 5: 诱导蛋白条带的切胶纯化产物。b) Western blotting 分析验证香鱼血清中 $\mathrm{aC} 9$ 成熟肽的 $\mathrm{N}$-糖基化, $\mathrm{ECL}$ 显影。1: 香 鱼血清, 未经 PNGase F 处理; 2: 香鱼血清, 经 PNGase F 处理; 3：原核 表达产物; NC: 空白阴性对照。

a) SDS-PAGE analysis of prokaryotic expressed ayu aC9, stained by Coomassie brilliant blue G-250. M: protein molecular weight standards $(\times$ $10^{3}$ ); 1: BL21 plys E, induced by IPTG; 2: pET-28a (+)-transformed BL21 plys E, induced by IPTG; 3: pET-28a-aC9-transformed BL21 plysE, not induced by IPTG; 4: pET-28a-aC9-transformed BL21 plys E, induced by IPTG; 5: purified recombinant protein. b) The confirmation of posttranslational $\mathrm{N}$-glycosylation of aC9 by Western blotting, development by ECL. 1: ayu serum, not digested by PNGase F; 2: ayu serum, digested by PNGase F; 3: recombinant aC9 produced in E. coli; NC: Negative control.

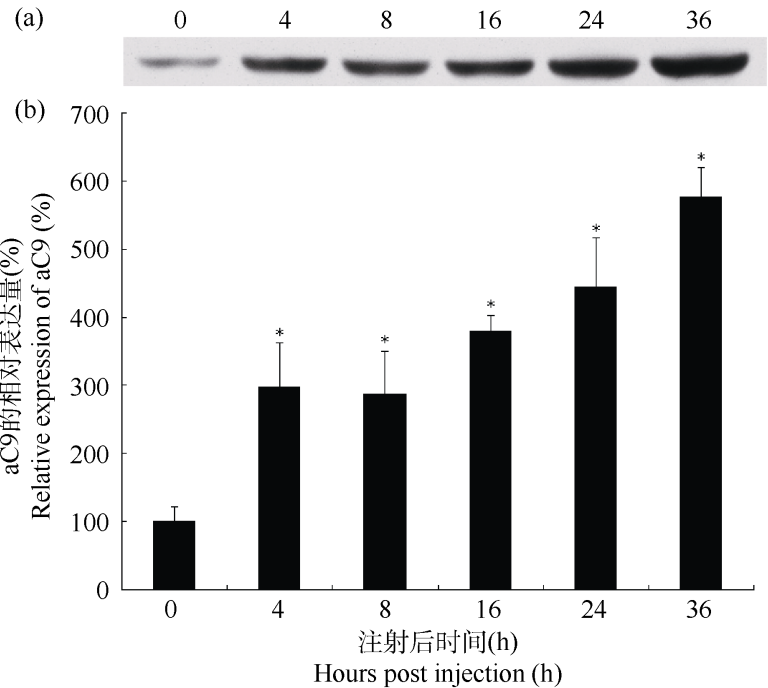

图 6 Western blotting 检测鳗利斯顿氏菌侵染 后香鱼血清 $\mathrm{aC} 9$ 含量变化

Fig.6 Western blotting analysis of ayu serum aC9 content during Listonella anguillarum infection

a: 各时间点香鱼血清中 $\mathrm{aC} 9$ 的 Western blotting 检测条带; b: $\mathrm{aC} 9$ 的 Western blotting 条带相对含量图示。*: 显著性差异 $(n=3)(P<0.05)$ 。 a: Western blotting analysis of ayu serum aC9 at different time post $L$. anguillarum infection; $\mathrm{b}$ : Quantification of the $\mathrm{aC} 9$ levels based on the Western blotting results shown in a. *: significant differences $(n=3)(P<0.05)$. 
香鱼血清中的 $\mathrm{aC} 9$ 含量持续增加, $4 \mathrm{~h}$ 时增加到正常 表达量的 3.0 倍, 至 $36 \mathrm{~h}$ 时, 达到正常表达量的 5.8 倍。

\section{3 讨 论}

本文采用文库随机测序结合 RACE 的方法, 获 得了香鱼补体成分 $a C 9$ 的全长 cDNA 序列。序列分 析表明, 香鱼 $\mathrm{aC} 9$ 具有已知的 $\mathrm{C} 9$ 特征性结构, 并且 鱼类 $\mathrm{C} 9$ 的 $\mathrm{C}$ 端比哺乳动物 $\mathrm{C} 9$ 多一个 $\mathrm{TSP} 1$ 结构域 (Tomlinson et al, 1993; Li et al, 2007), 但动物 C9 序 列的差异是否引起功能上的差异, 尚有待进一步研 究。香鱼 $\mathrm{aC} 9$ 存在翻译后的 $\mathrm{N}$-糖基化修饰, 这与已 报道的哺乳动物 C9 结果一致(Bunkenborg et al, 2004)。系统进化树分析表明, 鱼类 C9 和哺乳类 C9 分别成簇，香鱼 $\mathrm{aC} 9$ 与虹䲡 $\mathrm{C} 9$ 最相似。

组织表达特征研究揭示, 健康香鱼 $a C 9$ 基因 mRNA 主要在肝中表达, 脾中有一定量表达, 肠、 肌肉和鳃中也有少量表达, 其他组织中未检测到。 已知鱼类 $C 9$ 基因 mRNA 的组织表达特征有一定差 异, 如草鱼在血液、肌肉、表皮、肠、胸腺、鳃、 脾、肾、肝、脑、心和头肾等 12 个组织中均有表 达( Li et al, 2007), 而虹鳟则在脑、肠、肾、肝和脾 组织中表达(Chondrou et al, 2006)。

香鱼由于其经济价值, 近年来在中国的养殖面 积日益增加, 但病害问题严重, 其中鳗利斯顿氏菌
是养殖香鱼弧菌病的主要病原之一。因此, 有必要 对鳗利斯顿氏菌侵染后香鱼的免疫反应进行研究。 补体是鱼类免疫防御系统的重要组成成分, C9 参与 形成靶细胞表面攻膜复合物(MAC), 导致靶细胞溶 解。本文研究表明, 鳗利斯顿氏菌侵染后, 肝组织 中 $a C 9$ 基因 mRNA 显著增加, $16 \mathrm{~h}$ 时达到峰值, 到 $36 \mathrm{~h}$ 仍显著高于对照组, 揭示肝组织大量合成 $\mathrm{aC}$ 。 近期研究表明, 草鱼注射接种柱状黄杆菌 $(F$. columnare $) 1 \mathrm{~d}$ 后, 肝组织 $C 9$ 基因 mRNA 表达量显 著上调( Li et al, 2007); 患病毒性出血性败血症的 斑马鱼鯺中 $C 9$ 基因 mRNA 表达量上调 15.33 倍(Encinas et al, 2010), 与我们的结果吻合。香鱼 $a C 9$ 基因 mRNA 的表达模式与大部分肝内表达的急 性期反应蛋白 (acute phase protein, APP) 相似 (Witzel-Schlomp et al, 2001; Shi et al, 2010; Huang et $\mathrm{al}, 2011)$ 。免疫印迹研究表明, 细菌侵染后短期内, 香鱼血清 $\mathrm{aC} 9$ 的含量即显著增加，揭示它是一种 $\mathrm{APP}$ 。动物 APPs 的种类繁多, 结构和功能多种 多样，它们相互协调以去除炎症刺激物、弱化局 部炎症和促进组织修复和再生，从而使机体回 复到内稳态(Gerwick et al, 2002)。

综上所述，本文报道了香鱼补体成分 $a C 9$ 基因 的 cDNA 全序列，并对其在肝中的表达量变化与鳗 利斯顿氏菌侵染过程进行了相关研究，为鱼类抗细 菌免疫的深入研究奠定了基础。

\section{参考文献:}

Biesecker G, Gerard C, Hugli TE. 1982. An amphiphilic structure of the ninth component of human complement. Evidence from analysis of fragments produced by alpha-thrombin[J]. J Biol Chem, 257(5): 2584-2590

Bunkenborg J, Pilch BJ, Podtelejnikov AV, Wiśniewski JR. 2004. Screening for N-glycosylated proteins by liquid chromatography mass spectrometry[J]. Proteomics, 4(2): 454-465.

Chen J, Shi YH, Li MY, Ding WC, Niu H. 2008. Molecular cloning of liver angiotensinogen gene in ayu (Plecoglossus altivelis) and mRNA expression changes upon Aeromonas hydrophila infection[J]. Fish Shellfish Immunol, 24(5): 659-662.

Chondrou MP, Londou AV, Zarkadis IK. 2006. Expression and phylogenetic analysis of the ninth complement component (C9) in rainbow trout[J]. Fish Shellfish Immunol, 21(5): 572-576.

Dunkelberger JR, Song WC. 2010. Complement and its role in innate and adaptive immune responses[J]. Cell Res, 20(1): 34-50.

Encinas P, Rodriguez-Milla MA, Novoa B, Estepa A, Figueras A, Coll J. 2010. Zebrafish fin immune responses during high mortality infections with viral haemorrhagic septicemia rhabdovirus. A proteomic and transcriptomic approach[J]. BMC Genomics, 11: 518.

Endo Y, Matsushita M, Fujita T. 2011. The role of ficolins in the lectin pathway of innate immunity[J]. Int $J$ Biochem Cell Biol, 43(5): 705-712.

Fosbrink M, Niculescu F, Rus H. 2005. The role of c5b-9 terminal complement complex in activation of the cell cycle and transcription[J]. Immunol Res, 31(1): 37-46.

Gerwick L, Steinhauer R, Lapatra S, Sandell T, Ortuno J, Hajiseyedjavadi N, Bayne CJ. 2002. The acute phase response of rainbow trout (Oncorhynchus mykiss) plasma proteins to viral, bacterial and fungal inflammatory agents[J]. Fish Shellfish Immunol, 12(3): 229-242.

Huang ZA, Chen J, Lu XJ, Shi YH, Li MY. 2011. Alteration on the expression of ayu coagulation factor $\mathrm{X}$ gene upon Listonella anguillarum infection[J]. Zool Res, 32(5): 492-498. [黄左安, 陈畑, 陆 新江, 史雨红, 李明云. 2011. 香鱼凝血因子 $\mathrm{X}$ 基因表达与鳗利斯 顿氏菌感染的相关性[J]. 动物学研究, 32(5): 492-498.]

Katagiri T, Hirono I, Aoki T. 1999. Molecular analysis of complement component C8beta and C9 cDNAs of Japanese flounder, Paralichthys olivaceus[J]. Immunogenetics, 50(1-2): 43-48.

Li CH, Chen J, Shi YH, Li MY. 2009. Characterization of Listonella anguillarum as the aetiological agent of vibriosis occurred in cultured ayu (Plecoglossus altivelis) in Ninghai country, China[J]. Acta Micriobiol Sin, 2009, 49(7): 931-937. [李长红, 陈昫, 史雨红, 李明 
云. 2009. 宁海地区香鱼弧菌病病原菌鉴定[J]. 微生物学报, 49(7): 931-937.]

Li L, Chang MX, Nie P. 2007. Molecular cloning, promoter analysis and induced expression of the complement component $\mathrm{C} 9$ gene in the grass carp Ctenopharyngodon idella[J]. Vet Immunol Immunopathol, 118(3-4): 270-282.

Livak KJ, Schmittgen TD. 2001. Analysis of relative gene expression data using real-time quantitative PCR and the $2^{-\Delta \Delta C}{ }_{\mathrm{T}} \operatorname{method}[\mathrm{J}]$. Methods, 25(4): 402-408.

Muller-Eberhard HJ. 1986. The membrane attack complex of complement[J]. Annu Rev Immunol, 4(1): 503-528.

Qu HC, Ricklin D, Lambris JD. 2009. Recent developments in low molecular weight complement inhibitors[J]. Mol Immunol, 47(2-3): 185-195.

Rutkowski MJ, Sughrue ME, Kane AJ, Ahn BJ, Fang SN, Parsa AT. 2010. The complement cascade as a mediator of tissue growth and regeneration[J]. Inflamm Res, 59(11): 897-905.

Sarmar JV, Ward PA. 2011. The complement system[J]. Cell Tissue Res, 343(1): 227-235.

Shi YH, Chen J, Li CH, Li MY. 2010. Molecular cloning of liver Wap65 cDNA in ayu (Plecoglossus altivelis) and mRNA expression changes following Listonella anguillarum infection[J]. Mol Biol Rep, 37(3): 1523-1529.

Stanley KK, Herz J. 1987. Topological mapping of complement component $\mathrm{C} 9$ by recombinant DNA techniques suggests a novel mechanism for its insertion into target membranes[J]. EMBO J, 6(7): 1951-1957.

Tamura K, Dudley J, Nei M, Kumar S. 2007. MEGA4: Molecular evolutionary genetics analysis (MEGA) software version 4.0[J]. Mol Biol Evol, 24(8): 1596-1599.

Toapanta FR, Ross TM. 2006. Complement-mediated activation of the adaptive immune responses: role of $\mathrm{C} 3 \mathrm{~d}$ in linking the innate and adaptive immunity[J]. Immunol Res, 36(1-3): 197-210.

Tomlinson S, Stanley KK, Esser AF. 1993. Domain structure, functional activity, and polymerization of trout complement protein C9[J]. Dev Comp Immunol, 17(1): 67-76.

Uenobe M, Kohchi C, Yoshioka N, Yuasa A, Inagawa H, Morii K, Nishizawa T, Takahashi Y, Soma GI. 2007. Cloning and characterization of a TNF-like protein of Plecoglossus altivelis (ayu fish)[J]. Mol Immunol, 44(6): 1115-1122.

Wagner E, Frank MM. 2010. Therapeutic potential of complement modulation[J]. Nat Rev Drug Discov, 9(1): 43-56.

Witzel-Schlomp K, Rittner C, Schneider PM. 2001. The human complement C9 gene: structural analysis of the $5^{\prime}$ gene region and genetic polymorphism studies[J]. Eur J Immunogenet, 28(5): 515-522.

Yeo GSH, Elgar G, Sandford R, Breneer S. 1997. Cloning and sequencing of complement component $\mathrm{C} 9$ and its linkage to DOC-2 in the pufferfish Fugu rubripes[J]. Gene, 200(1-2): 203-211. 